NOTICE: this is the author's version of a work that was accepted for publication in Mathematics and Computers in Simulation. Changes resulting from the publishing process, such as peer review, editing, corrections, structural formatting, and other quality control mechanisms may not be reflected in this document. Changes may have been made to this work since it was submitted for publication. A definitive version was subsequently published in Mathematics and Computers in Simulation, 79, 9, 2009 DOI

10.1016/j.matcom.2008.09.001 


\title{
Evolution and governance of the biotechnology and pharmaceutical industry of China
}

\author{
Kai Wang, Jin Hong, Dora Marinova, Liang Zhu
}

\begin{abstract}
:
The high-speed growth of China's biotechnology industry during the past twenty years presents an excellent opportunity to examine its overall evaluation and governance from the perspective of science and technology policies. Although China's biotechnology industry has achieved tremendous extension both in scale and structure, the strengths it has gained from achievements in research and development activities have been significantly weakened in relation to processes of commercialization. After examining the definition of China's biotechnology industry as well as its evolution, the authors of this paper employ Actor-Networks Theory as a basic theoretical framework to reveal how China's biotechnology industry develops in the form of evolving networks within the country's social context and to identify what kinds of relationships exist among the relevant factors. Our hope is to provide guiding insights for improving the governance of China’s biotechnology industry both in policy and in management practices.
\end{abstract}

Keywords: Biotechnology and Pharmaceutical Industry, Evolution, Governance, Actor-Networks Theory (ANT)

\section{Introduction}

The past few decades witnessed the high-speed growth of China's biotechnology and pharmaceutical industry, which have currently become a focus of academic research not only in economics but in a large array of other fields such as management, sociology and policy studies [2, 21, 25]. Because of the strong relationships between biotechnology as an industry and as science and technology (S\&T) development, China's biotechnology industry can also serve as a study objective in S\&T Studies (STS). Therefore, a useful approach to examining its evolution can rise out of the sociology of S\&T [1, 12].

Biotechnology industry is one of the fastest-grow industries, thus has attracted researchers' interest and stimulated an array of studies [7, 8, 15, 16, and 17]. Obviously, there are many definitions of biotechnology $[18,19]$. Some of them focus on basic research while others put their emphasis on the technological application and commercialization. In this paper, however, we do not incline to put forward a single definition, it is actually the list-based definition of biotechnology, which is currently adopted by Chinese government, and such a definition is seen as appropriate one in our research. More importantly, the paper concentrates on industrialization and commercialization of biotechnology in China, where biotech industry is just emerging thus the systematic data cannot be acquired. So a broad and flexible definition does benefit our research.

Nowadays, from the viewpoints of China government and industry policymakers, the biotechnology industry mainly includes bio-pharmaceuticals, bio-agriculture, bio-energy, bio-manufacturing, bio-environmental protection, etc. During the $11^{\text {th }}$ five-year plan, Chinese government will launch 9 special projects, which are bio-pharmaceuticals, bio-agriculture, bio-energy, bio-manufacturing, bio-environmental protection, protection and exploitation of bio-resources, and the system of bio-safety management, so as to address the critical challenges from the fields such as health, food, energy, ecological and environmental issues. 
AS mentioned above, China's biotech-industry is not a mature one, and a systematic statistics and measurement does not exist at the present time. When the pharmaceutical industry is chosen as the topic of this paper, there are the following reasons. Firstly, bio-pharmaceuticals is the well-developed subset of the total biotechnology sector [4], therefore can reflect the trends and characteristics of China's biotech and High-tech industry. Secondly, bio-pharmaceuticals has been confirmed as the top priority in China Medium-to-Long-Term Plan for the Development of Science and Technology (2006 - 2020), 11th Five-year Plan for High-tech Industries Development as well as 11th Five-year Plan for Biotechnology industry Development. It certainly holds the great growth potential because it is taken as the vital sector to implement the state's catch-up strategy and a huge funding will be invested in the industry. Lastly, the pharmaceuticals, among which the bio-pharmaceuticals have been growing fastest, are listed in the inventory of High-tech industry of China (See Table1), and relatively systematical data can be obtained. Based on the reasons above, the pharmaceutical industry is thus taken as one of the best samples that can represent the development of the high technology industry and biotechnology industry.

\section{Table1}

In this paper, the bio-pharmaceutical industry is considered as the key point for systematically analyzing the evolution of the biotechnology industry of China. Employing Actor-Networks Theory as the main theoretical frame, we attempt to explore China's biotechnology industry both at the level of technology research and development (R\&D) and at the level of commercialization, in order to reveal how this industry develops in the form of networks within a social context and what kinds of relationships exist among any relevant factors thereby unknotting the problems that have emerged. The last section of this paper also considers the policy implications from our findings.

\section{Evolution of China's biotechnology industry}

China has a long history of biomedicine, and from the age of legend, traditional forms of biotechnology have existed. It is widely believed that Shen Nong who was generally regarded as the god of agriculture in China, invented a transparent stomach covering in order to observe the effects of herbal medicines on the digestive tract. In the Sui Dynasty (581-618), a vaccine against smallpox was developed, and during the Ming Dynasty (1368-1644), it became widely available to the masses. Despite this early inventiveness, China's biotechnology failed to go through the explosive changes as western science did in the $17^{\text {th }}$ to $19^{\text {th }}$ centuries. China never underwent such a scientific revolution as noted by Needham [14], until the foundation of the People's Republic of China in 1949. Soon after that, with the "Great Leap Forward" policy (which was initially launched in 1958 in an effort to catch up with, and try to surpass, the technological development of the industrially advanced countries) Chinese scientists succeeded first in the world in synthesizing the crystalline bovine insulin on Sept 17, 1965, signifying a crucial step in the course of understanding life and exploring its secrets. This discovery however did not even bring the first light of morning to the development of China's modern biotechnology industry.

In the 1970s, recombinant DNA approach was developed to isolate and characterize deoxyribonucleic acid (DNA), which allowed scientists to achieve hitherto unprecedented control over living systems [10]. The transfer of new genetic information into living organisms provides the means to produce valuable pharmaceuticals and to cure human genetic diseases. The development of biotechnology in the western countries was thus accelerated, however, China was still in the throes of the Cultural Revolution (1966-1976), and Chinese scientists had little chance to participate in developing modern biotechnology. It was not until 1978 that China's biotechnology as well as a great variety of 
scientific research programs was initiated in the "Spring of Sciences". The three stages in the development of China's biotechnology industry that followed are described below.

\subsection{First stage: initial starting}

In 1978, biotechnology was first mentioned as a focal point of China's S\&T development program. Following that, it became the top priority in the high technology field [9]. During the Sixth 5-Year Plan (1981-1985), funds were allocated to support biotechnology research in the fields of agriculture, food processing and pharmaceutical production. From 1981 to 1985, the funding for biological research increased more than 25-fold, and new mechanisms were introduced to allocate these monies by competitive, peer-reviewed grants. In 1983, the China National Center for Biotechnology Development (CNCBD) was established to coordinate the country's biotechnological research activities.

During the Seventh 5-Year Plan (1986-1990), the level and scope of biotechnology funding also increased greatly, and around 1989, China's investment in biotechnology, as a percentage of its gross national product, was comparable to that in many western countries. Early in March 1986, the State Council Leading Group on S\&T of China published a pivotal document and launched "The National High Technology Research and Development Program of China", regularly referred to as the "863 Plan", and biotechnology as the top priority in China's high technology development program was confirmed in it. In the same year, the National Natural Science Foundation of China (NSFC) came into being to support biotechnology as well as other basic research. In 1988, the State Science and Technology Commission (SSTC) published the white paper on S\&T in China, which reinforced biotechnology as China's number one priority for high technology development. These events in effect set the stage for the current mechanisms for determining biotechnology research priorities, administration and funding. In this period, the total investment in China's biotechnology and closely related fields was approximately 100 million yuan, or 20 million yuan per year. Grants were provided mainly through the Chinese Academy of Science (CAS) and the Ministries of Agriculture, Public Health, Medicine and Light Industry. Take 1987 for instance, 108 projects out of a pool of 150 applications were approved and supported; the average grant was 200,000 yuan, and certain key projects were funded up to 2 million yuan. The areas of research solicited and funded by the Seventh 5-Year Plan basically focused on basic genetic engineering, plant genetic engineering, chromosome engineering, cell engineering, enzyme engineering, downstream processing and bioengineering products.

China started to show interest in presence on international markets but the number of registered foreign patents was rather small. During 1978-1995, there were only 150 US patents (105 for pharmaceuticals and 92 for biotechnology products) by Chinese nationals. By the end of 1996, two new types of research centers were inaugurated in China to promote the development and commercialization of research outcomes in this field. Located respectively at Jiangmen and Shanghai, the first were two Biotechnology Bases designed to bring research results to the production stage. The second type included ten State Key Laboratories (See Table 2), which carried out most of the basic research and provided scientific research training for scientists from throughout China.

\subsection{Second stage: steady growth}

During the Ninth 5-Year Plan (1996-2000), China's biotechnology industry embraced the stage of steady growth in scale. There were 39 publicly trading biopharmaceutical firms in China by 2000, and China had co-operated with 152 countries in science and technologies and signed bilateral S\&T co-operation agreements with 99 governments [5]. During this period, the biotechnology sector enjoyed substantial scientific success and grew steadily to a considerable size. China's ambition for a presence in 
the global market was demonstrated with a total of 217 (156 pharmaceutical and 177 for biotechnology products) patents registered in USA.

\section{Table 2}

Take China's bio-pharmaceutical industry for example, recombinant human interferon Europium alb, the first Chinese production of genetically engineered drugs, which is also the world's first genetic engineering drugs using Chinese gene cloning and expression, was developed in 1989, and it is so far the only one with self-owned intellectual property developed independently by Chinese scientists. Following that, the bio-pharmaceuticals grew at a high speed: 12 genetic engineering pharmaceuticals came into the market of China in 1996, the proceeds of sale of 0.22 billion yuan of 1996 increased to 0.72 billion yuan in 1998 and 2.28 billion yuan in 2000 with an average annual growth rate of 79\% [4]. In 1996, the output value of biotechnology pharmaceuticals was approximately 1.8 billion yuan with profits of 0.5 billion yuan, while one year later, the output value increased to 3 billion yuan, and at the end of 2000, this number doubled to 6.9 billion yuan. The added value of pharmaceutical industry also increased drastically, and there were more than 300 enterprises producing more than 20 bio-technological pharmaceuticals in China in 2000.

Notwithstanding the progress made during the period of the Ninth 5-year Plan, China's biotechnology industry confronted a series of problems which would impede its further development. As the situation in the first period, biotechnology research were still remained funded almost entirely by the Chinese government in the Ninth 5-year Plan [20]. Although there were hundreds science-based companies and research institutes, the biotechnology sector remained largely an academic affair because of the poor ability and capacity in commercialization of scientific research outcomes, especially, in China's bio-pharmaceutical field. Few patented drugs were developed with commercial purpose. Even worse, missing out the opportunity in small molecule and antibody therapy restricted the market expansion of China's bio-pharmaceutical industry in its most recent stage.

\subsection{Third stage: accelerated extension}

From 2001, the Chinese government started the Tenth 5-year Plan (2001-2005), in this period, the development of China's biotechnology industry was characterized by the accelerated extension: the annual output of the Chinese fermentation industry stood at US\$ 20 billion; nearly 400 thousand tons of industrial enzymes are produced in China every year; its bio-diesel production capacity was about 100,000 tons and China had the world-leading enzymatic technology for bio-diesel production. The annual production of methane was approximately 5.6 billion cubic meters, and China had become the largest producer of antibiotics, glutamic acid, citric acid and vitamin C. The number of US patents with Chinese inventors was almost doubled to 414 (238 for pharmaceutical and 270 for biotechnology products). By the end of this period, as presented in pharmaceuticals in China and its development (See Table 3), each indicator of the whole pharmaceutical industry had greatly exceeded the plan: industrial output value, industrial added value and total profits were more than doubled those of the Ninth 5-year Plan [6].

\section{Table3}

Apart from the expansion in industrial scale, the economic structure of China's bio-pharmaceutical industry was further improved in this period. By accelerating the organizational structure adjustment and enlarging their sizes via recombination and shareholding reforms, a number of large-scale enterprises became listed in the Shanghai and Shenzhen stock exchanges. In the meantime, many small and medium-sized enterprises (SMEs) were still confronted the lack of intellectual property rights, the low R\&D expenditure and technological inferiority, which was determined by the industry's inborn high 
demands in technology, capital and R\&D resources. Nevertheless, during the Tenth 5-year Plan period, especially after China gaining membership of the World Trade Organization (WTO), an increasing number of foreign-funded enterprises surged into China for China's high-end bio-pharmaceutical market. While forcing the domestic bio- pharmaceutical enterprises to constantly reform and integrate so as to improve their degree of concentration and competitive ability, giant foreign-funded enterprises would also wash out completely most SMEs. Together with the inner-industry or cross-industry merger and reorganization in bio-pharmaceuticals, the structure of China's biotechnology industry became much better balanced.

In this stage, biotechnology research and industrial development in China stepped into a new era with the creation of a national biotechnology leadership group. Funding for biotechnology research came from two sources: government and enterprises. From 2000 to 2005, the Chinese government altogether spent about 10 billion yuan on biotechnology research mainly through the Ministry of Science and Technology (MOST), NSFC, CAS and relevant local government; among these, MOST administrated more than half of the government funding. Besides government funding, companies were estimated to invest roughly 500 million yuan. As a result of the strong emphasis on research and development, 30 types of new biotech-drugs were commercialized in this period, and over 150 biotechnology products were in clinical trials, the annual growth rate of the bio-pharmaceutical industry was over $20 \%$.

\section{Actor-Networks and governance of China's biotechnology}

From 1996 onwards, the industrial scale and structure of China's biotechnology industry have been improved tremendously, however, the past twenty years also saw the strength this industry gained from basic research was significantly weakened, namely the progression to commercialization, the comparatively limited scale of the whole industry, innovation-lacking products and poor output from R\&D. It is commonly assumed that these issues were caused by a set of somewhat vague and inappropriate governance. However after examining closer China's biotechnology industry within the model of Actor-Networks Theory (ANT), we argue that besides government bodies, enterprises and R\&D organizations, a diverse array of factors should be taken into account as we tackle emerging issues in the systematic study of the development of China's biotechnology industry, furthermore, these factors and groups are in fact all knitted into networks and act as both knitters and knots. China's biotechnology industry gains its strength to develop and evolve from these networks.

\subsection{Actor-Networks Theory}

Initially created in an attempt to examine processes of innovation and knowledge-creation in S\&T, ANT was first put forward by Michel Callon and Bruno Latour, in the early 1980s [24]. By analyzing large scale technological developments in an even-handed manner to include political, organizational, legal, technical and scientific factors and insisting on the agency of nonhumans, ANT maps the simultaneously material and semiotic relations in heterogeneous associations of humans and nonhumans, so as to explain how material-semiotic networks come together to act as an apparently coherent whole and to explore how actor-networks are formed to hold themselves together or fall apart. Since 1990, ANT has been widely adopted as an approach for analysis of heterogeneous relations among organizations in the fields of health studies, sociology, anthropology, feminist studies economics and so forth.

As one of the core concepts in ANT, translation also serves as the basic tool for understanding the development of technology. In the course of translation, innovators attempt to create a forum, a central 
network in which all the actors agree that the network is worth building and defending. Four moments of translation are defined by Michel Callon ([3]; en.wikipedia.org): Problematisation, Interessement, Enrolment and Mobilization. The first moment allows getting delegates representing various groups of actors identified, including the primary actor who tries to establish itself as an Obligatory Passage Point (OPP) between the other actors and the network, therefore making itself indispensable. Interessement makes the actors interested therefore negotiate the terms of their involvement. The primary actor now works to convince the others that the roles it has defined for them are acceptable. During Enrolment, the actors accept the roles that have been identified for them, which results in the enrolment of all relevant human and nonhuman factors as Actants. The last moment, Mobilization, ensures the enrolment is actively supported, and the delegate actors adequately represent the masses.

Holding the rationale that differences between human actors and nonhuman ones are generated in the network of relations, it should not be presupposed, ANT argues that all the elements in a network, human and nonhuman, can and should be described in the same terms. This is called the principle of generalized symmetry. Furthermore, it talks of Actants to denote human and nonhuman actors, and to assume that the actors in a network take the shape that they do by virtue of their relations with one another. It also assumes that nothing lies outside the network, and suggests that there is no difference in the ability of technology, humans, animals or other nonhumans to act. The ANT model notes that as soon as an actor engages with an actor-network, it is caught up in the web of relations and becomes part of the entelechy too.

Actor-networks should be seen as shifting systems of alliances, which include human and non-human factors [22]. The networks have to be continually maintained and renewed through the enrolment of the actors involved as well as the interactions between those different actors.

\subsection{Actor-Networks in China's biotechnology industry: a pharmaceutical case}

The set of reforms has set China's biotechnology and pharmaceutical industry on a solid footing as an innovation system, through the reorganization of R\&D organizations, economic institutions and governments, with the promotion of heterogeneous relationships among various actors embedded in the social context. Nevertheless, the networks of the Chinese biotechnology and pharmaceutical industry are still confronted with instability, which in the large extent cause biotechnological products to be hard to move from the laboratory to the market. The excellence in science as well as the expertise available in universities and public research institutions is far from being exploited to their full potential.

\section{Figure 1}

The actor-world of the pharmaceutical industry of China contains numerous actants and complex relationships between them, which determine the formation and evolution of the network (See Fig. 1). From the initial stage of development, the Chinese government has retained the position of OPP between actors and networks in the biotechnology and pharmaceutical industry. Some evidences of this are the funding for biology research and industrial development in China coming mainly from government (See Table 4), as well as the Government's role of the policymaker. The governance of the industry involves ministries such as National Development and Reform Commission, State Food and Drug Administration, Ministry of Health, State Administration of Traditional Chinese Medicine and Ministry of Commerce. NDRC is in charge of strategic planning and mid-to-long-term planning for the Chinese pharmaceutical industry, regulating the prices of drugs, managing disaster relief funds and carrying out the pharmaceutical development projects sponsored by the government. Ministry of Health guides the reform of the medical service industry, is responsible for clinical trials and clinical applications of drugs, it also joins with other agencies in monitoring the severe side effects of drugs and makes the basic 
insurance drug list. Ministry of Commerce regulates the import and export of medical devices and equipment, collects and analyzes import and export data, and carries out anti-dumping investigations.

Notably, SFDA is the key actant, as a translator as well as obligatory point passage, in this actor-network of the industry, which oversees all drug manufacturing, trade, and registration. SFDA has also experienced an institutional evolution. As part of the government restructuring announced in March 1998, the Ministry of Health's Department of Drug Administration merged with the State Pharmaceutical Administration of China (SPAC) to form the State Drug Administration (SDA). In 2003, the SDA was restructured and became the State Food and Drug Administration. Nowadays, its new regulations still follow the FDA's model. By policies and standards, SFDA, to a large extent, confirms the list of companies and products in this industry, and defines their identity and the role they should play.

Furthermore, these ministries put forward policies and laws to regulate the market and the industry. Through the national system of administration, the Chinese government strengthens the linkage between the enrolled actors after getting delegates representing the groups of actors identified, so as to enable the actors to negotiate the terms of their involvement while holding that their roles assigned by government are acceptable. By mobilization, the networks of China's pharmaceutical industry become widely supported, and the delegate actors in the network adequately represent the masses. Therefore, the interests of different human and nonhuman actors were translated into the interests of the whole networks and lead to the formation of this actor-world, as demonstrated in Fig. 1.

Except the ministries, there are pharmaceutical companies, domestic, foreign or joint-venture. Presently, the number of pharmaceutical companies is larger than 5000, and a large part of them are bio-pharmaceuticals companies. In 2000, the biopharmaceutical industry in China was valued at US\$870 million; there are more than 200 companies engaged in the R\&D of genetically engineered drugs, and 67 companies were listed on the Shanghai and Shenzhen Stock Exchanges [11]. These companies promote the formation of this act-network and play a critical role, but the pharmaceutical industry of China is highly fragmented, no any single company can control the network and interaction.

In the R\&D section of biotechnology, networks made by human actors, mainly scientists, engineers and administrative staff, and nonhuman actors (funding, facilities and so forth) are linked by varied R\&D programs. These programs are generally initiated by the Chinese government launching the translation of interests. During the moments of translation, the formation and stability of networks are ensured by funding and administration mainly from MOST (which conducted 973, 863, Torch, and Special Programs), NSFC (which focused on basic research), National Development and Reform Commission (NDRC) specializing in industry development and industrial policy, the State Food and Drug Administration (SFDA), CAS supporting related institutes, and Ministry of Education (MOE) regulating universities involved. Among them, the Bureau of Life Science and Biotechnology affiliated with the Chinese Academy of Science and Bureau of High-tech Industry in NDRC well demonstrate the OPP position the Chinese government has set for itself in the networks. With 21 research institutes, 3 biotech research bases (Shanghai, Beijing, West-South China), over 6000 R\&D personnel, 7 focused research area, 2 Priority development areas (Biotechnology and Pharmacy), the Bureau created a token of China's biotechnology R\&D in the form of network.

\section{Table4}

The successful formation and consolidation of networks guaranteed the accelerated development of China's biotechnology industry. China's participation as the only developing country in the Human Genome Project (HGP) and Chinese researchers successfully sequencing $1 \%$ of the human genome with an accuracy rate of 99\%, all showcased the country's capability in biotechnological research [2]. 
Nevertheless, both the quality and stability of China's biotechnology industry networks are open to be improved. There are currently approximately 500 bio-pharmaceutical companies in China with annual sale proceeds of about 34 billion yuan; however, the share they occupy in the whole global pharmaceutical market is less than $10 \%$. The lack of group-scale enterprises, poor competitive power, innovation-lacking products, pressure from foreign-owned enterprises' entering and further limitations are weakening the strength of China's biotechnology industry networks.

\section{Conclusion: policy implications}

Biotechnology continues to be the top priority in China's 2006-2020 S\&T Development Plan [5]. Despite the rapid growth achieved in the past twenty years, China's biotechnology industry still has a large range of restricting actors which severely threaten the stability of whole networks. Among these actors, limited funding, low investment, insufficient research personnel and domestic collaboration are ranked at the top of list.

The shortage of financing options creates the first major bottleneck for the Chinese biotechnology industry. The government remains the main source of funding for R\&D and commercialization, while China's biotechnology enterprises also find it particularly difficult to attract investment due to the short-term expectations of the Chinese investor community. Investors in China are commonly interested in returns on investment that can be received more rapidly than what is typical for health biotechnology ventures renowned for their risky nature and protracted development times. As a result, Chinese companies have steered away from high-risk, capital-intensive R\&D activities and concentrated on commercialization of more mature and less risky technologies such as in generic manufacture (see Figure 2). The best-fitted empirical model of expenditures for new pharmaceutical products (on Figure 2) shows a rapid polynomial increase in recent years, which may even become an exponential growth (dotted line on Figure 2) as time goes by and more investment being attracted by this industry (hence more observations added to the curve).

Insufficient research personnel and domestic collaboration resulting from the scattered industrial structure are also challenging the stability of China's biotechnology industry (See Table 5). Even worse, according to a Ministry of Personnel (MOP)'s estimation, about 580,000 Chinese students have left the country to study abroad since the late 1970s, with only about 160, 000 returning [12]. Of the nearly 300,000 Chinese students overseas at present, one-third are involved in the biotechnology field. This seriously limits the source of research personnel supply. On the other hand, although universities and public research institutions are capable of carrying out world-class research, their activities are not connected to the budding industrial sector. Patent statistics reveal that public research institutes and universities own $80 \%$ of all biotechnology patents, however, only $6 \%$ of new biotechnology therapeutics and vaccines in China are the result of joint developments by universities and enterprises [13].

Figure2

Table5

Along with the growing foreign-capital investment and rapid reforms and reorganization among domestic enterprises, we argue, it is an optimized choice for domestic biotechnology enterprises to establish a sound competitive cooperation. Furthermore, several large-scale groups should be established via strategic alliances such as mergers and acquisitions. In this way, market expansion and enhancement of strength can be achieved with an enlarging enterprise scale and trade value. To overcome the barriers of limited funding and low investment, the Chinese government needs to take measures such as simplifying foreign investment procedures, protecting the natural environment and improving 
infrastructure so as to make the investment environment more attractive. It is even more important to construct an industrial culture within the networks of China's biotechnology industry. Cultural differences between foreign investors and Chinese staff can seriously delay the enrollment of foreign investment to the actor-networks of China, since the cultural differences between nations cannot be removed within a short time; the constructing of acceptable industrial culture thus becomes crucial.

To deal with the insufficiency of research personnel and domestic collaboration, we argue, a national system of innovation should be set. Taking its advanced capability in genomics/ genetics research, the networks of China's biotechnology industry can translate their interests into that of the innovation system which is promising in creating the waves of returnees from overseas [23], also in the networks of larger scale effectiveness of the overall operation of highly talented and skilled scientists.

\section{Acknowledgment}

We wish to thank the anonymous reviewers and the senior editor of this issue for their very useful comments. The third author wants to acknowledge the support of the Australian Research Council. The remaining three authors wish to acknowledge the support of the National Social Science Foundation of China, and National Innovation Centre for Science and Technology History and Civilization, University for Science and Technology of China (USTC).

\section{References}

[1] M. Biagioli, The Science Studies Reader, Routledge, 137-160 (1999).

[2] H. Breithaupt, China's Leap forward in Biotechnology, EMBO Reports, 4, 111-113(2003).

[3] M. Callon, et al. (ed.), Mapping the dynamics of science and technology, The Macmillan Press(1986).

[4] Department of High Technology Industry Development of Commission of National Development Planning, and Chinese Academy of Bioengineering (DHTID), (2003), Report on Development of Chinese Bio-technology, 2002, Chemical Industry Press, Modern Bio-technology and Medical Science and Technology Centre, Beijing.

[5] H. Ding, Bio-industry R\&D in China, Finpro Tekes China Silk Road Biotech Project, Finpro Shanghai, June, (2007).

[6] F. Fang, China Pharmaceutical Industry Report, http://www.researchinchina.com/. (2006-7).

[7] S. Giesecke, The contrasting roles of government in the development of biotechnology industry in the US and Germany, Research Policy, Vol.29, 2, 205-223 (2000).

[8] L. Hall, S. Bagchi-Sen, An analysis of firm-level innovation strategies in the US biotechnology industry, Technovation 27, 4-14(2007).

[9] D. H. Hamer, S. Kung, Biotechnology in China. National Academy Press, 3-16 , Washington, DC. 1989.

[10] T. Hara, Innovation in the Pharmaceutical Industry, Edward Elgar, 292 pp. Cheltenham, UK. ,2003.

[11] Y. Jiang, et al., Chinese pharmaceutical companies: an emerging industry, Drug Discovery Today, Vol.6, No.12, 610-612(2001).

[12] Z. Li, et al., Health biotechnology in China - reawakening of a giant, Nature Biotechnology, Vol. 22 Supplement (2004). 
[13] Y. Liu, Development of Biotechnology Industry and its Impacts in China, SEPA, December 11, Paris, (2006).

[14] J. Needham, Science and Civilisation in China, Cambridge University Press, London, 1954.

[15] G. Pisano, The governance of innovation: Vertical integration and collaborative arrangements in the biotechnology industry, Research Policy, Vol.20, 3, 237-249 (1991).

[16] W. Powell, Interorganizational Collaboration and the Locus of Innovation: Networks of Learning in Biotechnology, Administrative science quarterly, 41, 116-145(1996).

[17] J. Senker, National innovation system, organizational learning and Industrial biotechnology, Technovation, 16(5), 219-229 (1996).

[18] D. Springham, Biotechnology:the science and the business, Second Edition, Harwood Academic Publishers, 1999.

[19] B. van Beuzekom, A. Arundel (2006), OECD Biotechnology Statistics - 2006, OECD.

[20] J.Z. Wang, The Research and Quality Control of Medical Bio-technology, Science Press, Beijing, 2002.

[21] S. White, X. Liu, Organizational processes to meet new performance criteria: Chinese pharmaceutical firms in transition, Research Policy, 27 369-383(1998).

[22] B. Williams-Johns, J. Graham, Actor-networks theory: a tool to support ethical analysis of commercial genetic testing, New Genetics and Society, Vol. 22, No.3, 271-296 (2003).

[23] G. Wong, Chinese biotech: the need for innovation and higher standards, Journal of Nature Biotechnology, 24, 221 - 222(2006).

[24] S. Yearley, Making Sense of Science, Sage Publications, 226 pp. London, (2005).

[25] G. Yeung, The Implications of WTO Accession on the Pharmaceutical Industry in China Journal of Contemporary China, 11(32), 473-493(2002). 
Figure 1

Actor-network in Biotech and Pharmaceutical Industry of China

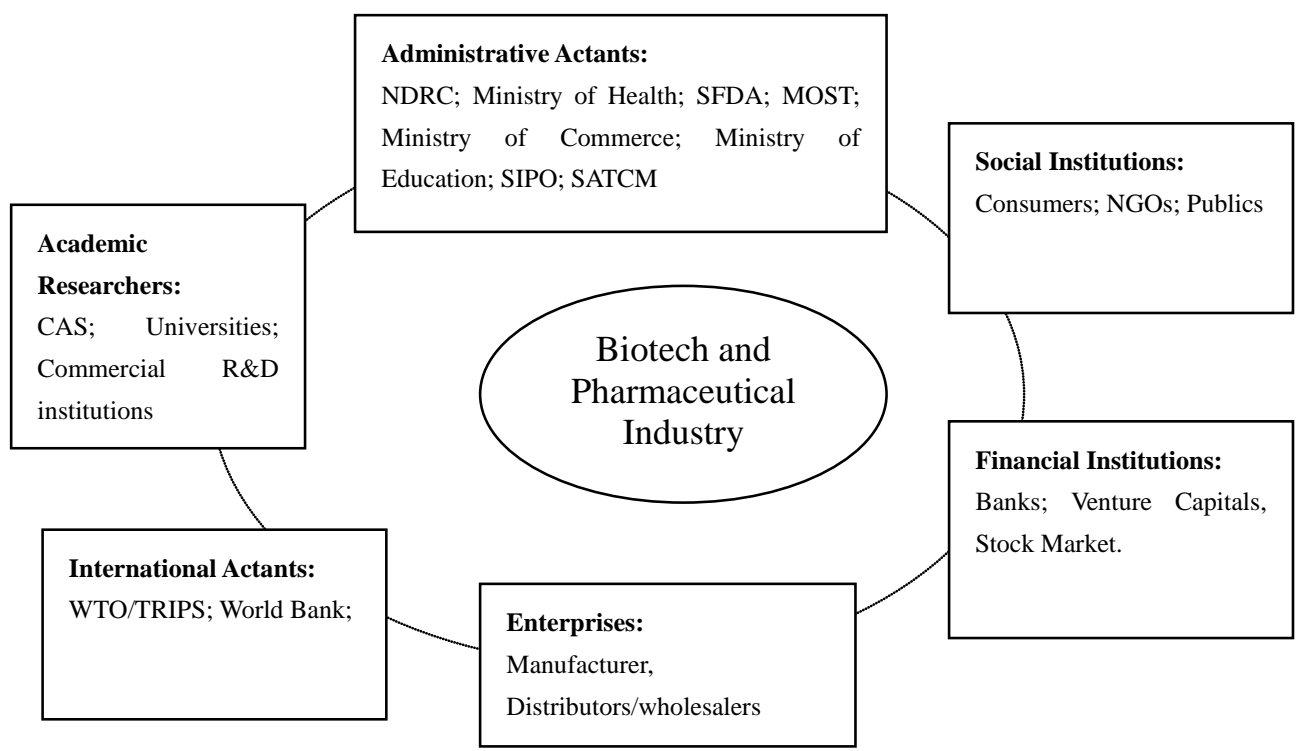

Note: NDRC: National Development and Reform Commission; SFDA: State Food and Drug Administration; MOST: Ministry of Science and Technology; SIPO: State Intellectual Property Office; SATCM: State Administration of Traditional Chinese Medicine 
Figure 2.

Expenditure for new products of pharmaceutical industry (100 million yuan) and empirical models

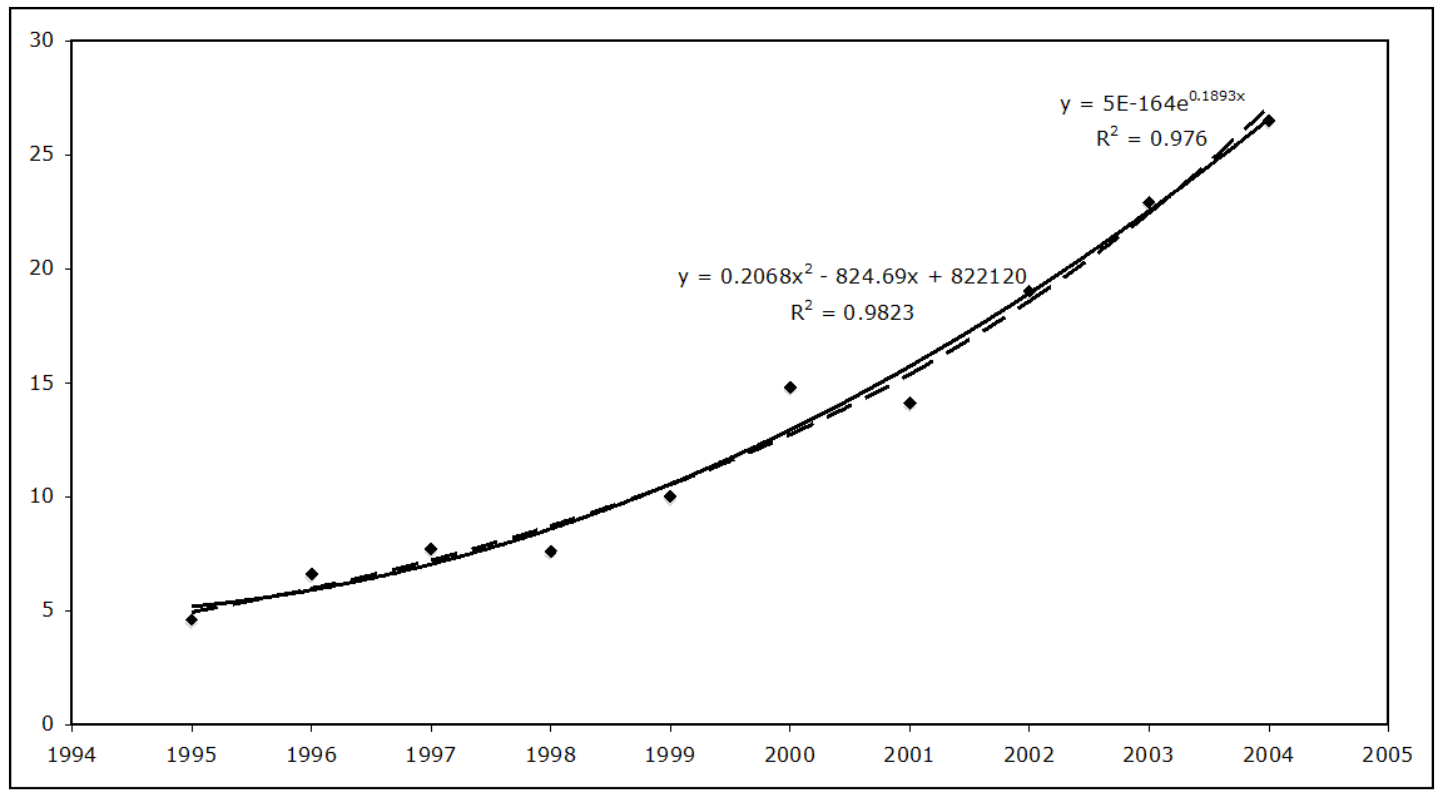

Data source: National Bureau of Statistics, China Statistics Yearbook on High Technology Industry (2004). 
Table1

Value added of high-tech industries. 100 million Yuan

\begin{tabular}{lllll}
\hline & $\mathbf{1 9 9 8}$ & $\mathbf{2 0 0 0}$ & $\mathbf{2 0 0 2}$ & $\mathbf{2 0 0 4}$ \\
\hline Pharmaceuticals & 433 & 634 & 835 & 1173 \\
\hline Aircraft and spacecraft & 87 & 106 & 149 & 149 \\
\hline $\begin{array}{l}\text { Electronic and telecommunications } \\
\text { equipment }\end{array}$ & 870 & 1471 & 1939 & 3366 \\
\hline Computers and office equipments & 266 & & 604 & 1226 \\
\hline Medical equipments and meters & 129 & 374 & 242 & 427 \\
\hline Total & 1785 & 174 & 3769 & 6341 \\
\hline
\end{tabular}

Source: National Bureau of Statistics et al, China Statistics Yearbook on High Technology Industry (2005). 
Table 2

China’s State Key Laboratories in biotechnology

\begin{tabular}{|c|c|c|}
\hline $\begin{array}{c}\text { Year of } \\
\text { Establishment }\end{array}$ & Location & Name \\
\hline 1984 & FuDan University, Shanghai & State Key Lab of Genetic Engineering \\
\hline 1985 & Beijing University, Beijing & State Key Lab of Natural and Biomimetic Drugs \\
\hline 1985 & $\begin{array}{c}\text { Shanghai Cancer Institute \& Jiaotong } \\
\text { University, Shanghai }\end{array}$ & State Key Laboratory of Carcinogenesis \\
\hline 1989 & Zhong’nan University, Hu'nan & National Lab of Medical Genetics of China \\
\hline 1991 & Nanjing University, Jiangsu & State Key Lab of Pharmaceutical Biotechnology \\
\hline 1991 & Academy of Science, Beijing & State Key Lab of Medical molecular biology \\
\hline 1991 & $\begin{array}{c}\text { Shanghai Institute of Material Medica, } \\
\text { Academy of Science, shanghai }\end{array}$ & State Key Lab of New Drug Research \\
\hline 1991 & $\begin{array}{c}\text { East China University of Sci \& Tech, } \\
\text { shanghai }\end{array}$ & State Key Laboratory of Bioreactor Engineering \\
\hline 1992 & FuDan University, Shanghai & State Key Lab of Medical Neurobiology \\
\hline 1996 & Qinghua University, Beijing & Lab of Structural Biology \\
\hline
\end{tabular}


Table 3

Pharmaceuticals in China and its Development

\begin{tabular}{|c|c|c|c|c|c|}
\hline & 2002 & 2003 & 2004 & 2005 & 2006 \\
\hline Firm Number & 3586 & 4076 & 4397 & 5308 \\
\hline Assets (billion Yuan) & 361.5 & 429.8 & 479.8 & 549.0 & 613.6 \\
\hline Sales (billion Yuan) & 22.1 & 275.1 & 321.3 & 402.0 & 473.7 \\
\hline Profits (billion Yuan) & 20.1 & & & & 33.6 \\
\hline
\end{tabular}

Source: National Bureau of Statistics of China 
Table 4

R\&D by source of funds and sector of performance, 2004 (billion yuan)

\begin{tabular}{|l|c|c|c|c|c|}
\hline & \multicolumn{5}{|c|}{ Performance sectors } \\
\hline Source of funding & Research institutes & Enterprises & Universities & Others & Total \\
\hline Government & 344.3 & 62.6 & 108.8 & 7.8 & 523.6 \\
\hline Enterprises & 22.4 & 1189.3 & 74.5 & 5.1 & 1291.3 \\
\hline Abroad & 2.6 & 19.8 & 2.6 & 0.1 & 25.2 \\
\hline Others & 62.4 & 42.3 & 14.9 & 6.6 & 126.2 \\
\hline Total & 431.7 & 1314.0 & 200.9 & 19.7 & 1966.3 \\
\hline
\end{tabular}

Source: Annual S\&T report, MOST 2005 
Table 5

Biotechnology industry by country

\begin{tabular}{|c|c|c|c|c|}
\hline Item & China & India & USA & Germany \\
\hline $\begin{array}{c}\text { Bio-tech } \\
\text { Company }\end{array}$ & $>500$ & 240 & 1460 & 14,000 \\
\hline Personnel & 50,000 & 25,000 & 140,000 & - \\
\hline Laboratory & 400 & - & 500 & - \\
\hline R\&D Personnel & 20,000 & - & 5 bio-tech zone & - \\
\hline
\end{tabular}

Source: Bio-industry in China annual report 2005 